\title{
Iloprost reverses established fibrosis in experimental right ventricular failure
}

\author{
Jose Gomez-Arroyo ${ }^{1}$, Masahiro Sakagami ${ }^{2}$, Aamer A. Syed ${ }^{1}$, Laszlo Farkas ${ }^{1}$, \\ Benjamin Van Tassell ${ }^{1,3}$, Donatas Kraskauskas ${ }^{1}$, Shiro Mizuno ${ }^{4}$, \\ Antonio Abbate ${ }^{1,3}$, Harm J. Bogaard ${ }^{5}$, Peter R. Byron ${ }^{2}$ and Norbert F. Voelkel ${ }^{1}$ \\ Affiliations: ${ }^{1}$ Victoria Johnson Center for Lung Obstructive Disease Research, Virginia Commonwealth \\ University, Richmond, VA, USA. ${ }^{2}$ Dept of Pharmaceutics, School of Pharmacy, Virginia Commonwealth \\ University, Richmond, VA, USA. ${ }^{3}$ VCU Pauley Heart Center, Virginia Commonwealth University, Richmond, VA, \\ USA. ${ }^{4}$ Division of Respiratory Diseases, Kanazawa Medical University, Ishikawa, Japan. ${ }^{5}$ Dept of Pulmonary \\ Medicine, VU University Medical Center, Amsterdam, The Netherlands.
}

Correspondence: Jose Gomez-Arroyo, Dept of Anesthesiology and Critical Care Medicine, Johns Hopkins University, 720 Rutland Avenue, Ross 361, Baltimore, MD, 21224, USA. E-mail: jgomeza1 djhmi.edu

ABSTRACT Prostacyclin and its analogues improve cardiac output and functional capacity in patients with pulmonary arterial hypertension (PAH); however, the underlying mechanism is not fully understood. We hypothesised that prostanoids have load-independent beneficial effects on the right ventricle (RV).

Angio-obliterative PAH and RV failure were induced in rats with a single injection of SU5416 followed by 4 weeks of exposure to hypoxia. Upon confirmation of RV dysfunction and PAH, rats were randomised to $0.1 \mu \mathrm{g} \cdot \mathrm{kg}^{-1}$ nebulised iloprost or drug-free vehicle, three times daily for 2 weeks. RV function and treadmill running time were evaluated pre- and post-iloprost/vehicle treatment. Pulmonary artery banded rats were treated 8 weeks after surgery to allow for significant RV hypertrophy.

Inhaled iloprost significantly improved tricuspid annulus plane systolic excursion and increased exercise capacity, while mean pulmonary artery pressure and the percentage of occluded pulmonary vessels remained unchanged. Rats treated with iloprost had a striking reduction in RV collagen deposition, procollagen mRNA levels and connective tissue growth factor expression in both SU5416/hypoxia and pulmonary artery banded rats. In vitro, cardiac fibroblasts treated with iloprost showed a reduction in transforming growth factor (TGF)- $\beta 1$-induced connective tissue growth factor expression, in a protein kinase A-dependent manner. Iloprost decreased TGF- $\beta 1$-induced procollagen mRNA expression as well as cardiac fibroblast activation and migration. Iloprost significantly induced metalloproteinase- 9 gene expression and activity and increased the expression of autophagy genes associated with collagen degradation.

Inhaled iloprost improves RV function and reverses established RV fibrosis partially by preventing collagen synthesis and by increasing collagen turnover.

@ERSpublications

Prostanoids have load-independent effects on the right ventricle that could contribute to improvement in \#PAH http://ow.ly/Ae5Om

This article has supplementary material available from erj.ersjournals.com

Received: Oct 292013 | Accepted after revision: July 312014 | First published online: Sept 262014

Support statement: This work was partly funded by a grant from Actelion, supplemented by funds from the VCU's Medical College of Virginia Foundation. P.R. Byron and M. Sakagami received support from VCU's CTSA Grant (UL1TR00058) from the National Center for Advancing Translational Sciences. The VCU Nucleic Acids Research Facility core laboratory is funded by a NIH-CI Cancer Center Support Grant (P30 CA016059). Ventavis was provided by Actelion Pharmaceuticals (Allschwil, Switzerland) free of charge.

Conflict of interest: Disclosures can be found alongside the online version of this article at erj.ersjournals.com

Copyright @ERS 2015 


\section{Introduction}

Severe pulmonary arterial hypertension $(\mathrm{PAH})$ constitutes a group of chronic and frequently progressive lung diseases with a high morbidity and mortality [1]. While the primary pathobiological changes occur in the pulmonary circulation, patients with PAH very often die from right ventricular failure (RVF) $[1,2]$. For nearly two decades, intravenous administration of the synthetic prostacyclin epoprostenol has been a cornerstone of PAH treatment [3] and more stable prostacyclins, such as iloprost and treprostinil, have now become part of the treatment repertoire for PAH $[4,5]$. Because multiple studies have shown that prostacyclin treatment significantly increases cardiac output $[6,7]$, improves functional capacity [8] and has been associated with improved survival [9], prostanoids have become the recommended treatment for patients with severe PAH, particularly for those with severe right ventricle (RV) dysfunction [10]. Whereas it has been generally assumed that the therapeutic effect of prostacyclins is explained by pulmonary vasodilation and modulation of vascular remodelling [5, 11], many clinical trials have demonstrated a limited effect in reducing mean pulmonary arterial pressure [12], and there is recent evidence showing that lung vascular remodelling is not reduced even after long-term treatment [13, 14]. Because the mechanisms whereby prostacyclin treatment improves cardiac performance and functional capacity remain largely undetermined, we hypothesised that prostanoids have direct cardiac effects that improve RV function without necessarily affecting lung vascular remodelling. To test this hypothesis, we measured the effects of the prostacyclin analogue iloprost on two different rat models of chronically increased RV afterload. Our results demonstrate that inhaled iloprost significantly improved RV function and treadmill running time, without affecting the degree or form of vascular remodelling or reducing pulmonary arterial pressure. Strikingly, iloprost treatment reversed established RV fibrosis in a load-independent manner. The anti-fibrotic effects of iloprost appear to be partly explained by preventing collagen synthesis and by increasing collagen turnover. Some of these findings have been reported previously in abstract form [15].

\section{Methods}

Animal models, echocardiography, treadmill endurance and haemodynamic tests

For the SU5416/hypoxia (SuHx) model, severe angioproliferative PAH and RV dysfunction were induced in Sprague-Dawley rats (body weight: $220 \mathrm{~g}$; age: 4 weeks) with a single subcutaneous injection of the vascular endothelial growth factor (VEGF)-receptor blocker SU5416 at a dose of $20 \mathrm{mg} \cdot \mathrm{kg}^{-1}$ followed by 4 weeks of hypoxia (exposure to $10 \%$ oxygen in a normobaric environment), as described previously [16, 17]. For pulmonary artery banding $(\mathrm{PAB})$, surgical ligation of the main pulmonary artery was achieved through a left thoracotomy in male Sprague-Dawley rats weighing 180-200 g, tying a silk suture around an 18-gauge needle alongside the pulmonary artery, as described previously [16] and in the online supplementary material.

Following the 4 weeks of continuous hypoxia for the SuHx model, or 8 weeks after PAB, pre-dosing exercise endurance was determined and RV function was assessed by transthoracic echocardiography, as previously reported $[18,19]$. In the treadmill endurance test, SuHx rats were placed on a treadmill to run against an incline of $5^{\circ}$ at a speed of $15 \mathrm{~m} \cdot \mathrm{min}^{-1}$. Exhaustion was judged and recorded as the time at which the animals either received a fifth electrical shock or ceased running. For echocardiography the tricuspid annulus plane systolic excursion (TAPSE), which estimates RV longitudinal contraction, was used as a reference parameter to evaluate RV function, as previously reported [16, 20, 21]. A TAPSE value below $2.5 \mathrm{~mm}$ and the presence of a mid-systolic notch in the pulse-wave Doppler flow curves were used as indicators of the presence of severe RV dysfunction and PAH, respectively [22]. These parameters provided the two inclusion criteria used to randomise the rats to treatment with iloprost or drug-free vehicle. Rats were re-tested following 2 weeks of aerosol dosing with iloprost or drug-free vehicle. Exercise endurance tests and echocardiograms were performed $24 \mathrm{~h}$ after the last dose of inhaled treatment to allow for drug washout. After anaesthesia with ketamine/xylazine, rats were subjected to transthoracic echocardiography and subsequent haemodynamic measurements as reported previously [18]. Mean pulmonary artery pressure was measured via median sternotomy with a 4.5-mm Millar conductance catheter inserted into the pulmonary artery via the RV outflow tract as described previously [16, 18]. Left ventricular end-diastolic pressure was measured to calculate pulmonary vascular resistance.

\section{Inhalation protocol}

Ventavis was provided by Actelion Pharmaceuticals (Allschwil, Switzerland) and was used without dilution. The drug-free vehicle solution was prepared in-house, according to its prescribing information. Upon confirmation of PAH and RV dysfunction by echocardiogram, a group of rats received solution aerosols of iloprost (Ventavis) at a calculated lung dose of $0.1 \mu \mathrm{g} \cdot \mathrm{kg}^{-1}$, or drug-free vehicle, three times daily for 2 weeks. A detailed description of the custom-made, nose-only aerosol exposure system is included in the online supplementary material. The calculated lung dose of iloprost was based on earlier 
experiments in which aerosolised fluorescein isothiocyanate-labelled dextran, a nonabsorbable marker, was administered using the same exposure conditions used for iloprost dosing (fig. S1b).

\section{In vitro experiments}

Primary human cardiac fibroblast cells were cultured with fibroblast growth medium (Lonza, Basel, Switzerland). Cells were incubated for $24 \mathrm{~h}$ with either PBS, iloprost at $1 \mathrm{ng} \cdot \mathrm{mL}^{-1}$, recombinant human (rh) transforming growth factor (TGF)- $\beta 1$ at $2 \mathrm{ng} \cdot \mathrm{mL}^{-1}$, or iloprost at $1 \mathrm{ng} \cdot \mathrm{mL}^{-1}$ plus rhTGF- $\beta 1$ at $2 \mathrm{ng} \cdot \mathrm{mL}^{-1}$. In a separate experiment, another group of cells were concomitantly incubated with iloprost plus rhTGF- $\beta 1$ plus $0.4 \mathrm{nM}$ of the protein kinase A inhibitor 8-bromoadenosine-3', $5^{\prime}$-cyclic monophosphorothioate, Rp-isomer (8-rbs-cAMPS) (Sigma Aldrich, St Louis, MO, USA) [23]. All treated cells in these groups received a second dose of iloprost $\left(1 \mathrm{ng} \cdot \mathrm{mL}^{-1}\right)$ or vehicle $(1 \mu \mathrm{L}$ added to every dish) $12 \mathrm{~h}$ after the first dose without changing the medium. In a third separate experiment a group of cells was first treated with rhTGF- $\beta 1$ at $2 \mathrm{ng} \cdot \mathrm{mL}^{-1}$, and then treated with iloprost or vehicle $24 \mathrm{~h}$ and $36 \mathrm{~h}$ later (intervention group). After $24 \mathrm{~h}$ (or $48 \mathrm{~h}$ for the intervention group), cells were harvested and used for gene expression studies, immunohistochemistry or fibroblast migration analysis. For detailed information regarding the inhalation protocol, echocardiography, gene expression, protein expression, histology, vessel morphometry, fibrosis quantification, immunohistochemistry and zymography, see the online supplementary material.

\section{Statistical analysis}

Differences between groups were assessed using one-way, two-way or repeated-measures ANOVA tests as appropriate. Bonferroni's post hoc test was used to assess significant differences between groups. A p-value $<0.05$ was accepted as significant. Correlation analysis was carried out using Spearman's test. Results are reported as mean \pm SEM or fold-change over controls (mean \pm SEM), unless otherwise specified. Six to eight rats were used per group for gene expression analysis. Eight to 12 rats were used for echocardiographic or haemodynamic analysis. Four rats per group were used for treadmill exercise endurance tests. Four rats per group were used for tomato-lectin perfusion. Three rats per group were used for the PAB experiments. Statistical analysis was performed using PASW Version 18 (SPSS Inc., Chicago, IL, USA) and GraphPad Prism (La Jolla, CA, USA).

\section{Results}

Iloprost improves RV function and treadmill exercise capacity but does not affect pulmonary arterial pressure or lung vascular remodelling

As reported previously, SuHx rats developed severe angio-obliterative PAH and RVF [16, 18, 24, 25]. Inhaled iloprost treatment did not reduce the mean pulmonary arterial pressure (fig. 1a) and did not reduce the number of occluded vessels (fig. 1b). Plexiform-like lesions were consistently present in both groups (fig. 1c and d). Expression of the proliferating cell nuclear antigen was similarly increased in both groups, but did not appear to be different between iloprost- and drug-free vehicle-treated groups (fig. 1e and f). Interestingly, Western blot analysis from whole lung tissue lysates revealed a significantly decreased expression of the prostacyclin receptor (IP), which may partially explain the lack of response to iloprost on pulmonary vascular remodelling (fig. $1 \mathrm{~g}$ ).

Despite the absence of a change in RV hypertrophy (RV/left ventricle (LV)+interventricular septum (S)) (fig. 2a), iloprost-treated rats demonstrated a significant increase in cardiac output and TAPSE when compared with the drug-free vehicle-treated group (fig. $2 \mathrm{c}$ and d). Most importantly, iloprost-treated rats had a large improvement in treadmill exercise endurance when compared with the vehicle-treated group (fig. 2e) and this functional improvement correlated with an increase in TAPSE $\left(\mathrm{r}^{2}=0.54, \mathrm{p}=0.002\right)$ (fig. 2f). Although not significant, the increment in cardiac output was associated with a reduction in the estimated pulmonary vascular resistance in iloprost-treated rats (fig. 2g). There was no difference in systemic blood pressure or left ventricular contractility ( $\mathrm{d} P / \mathrm{d} t$ ) between groups (figs $\mathrm{S} 2 \mathrm{a}$ and $\mathrm{b}$ ).

\section{Iloprost does not improve capillary rarefaction and does not increase the gene expression of pro-angiogenic factors in maladaptive RV hypertrophy tissue}

Because prostacyclin induces the expression of VEGF-A (Vegfa) and promotes proliferation of lung endothelial cells in vitro $[26,27]$ and maladaptive/dysfunctional RV hypertrophy tissue is characterised by decreased Vegfa expression and capillary rarefaction [16], we initially postulated that inhaled iloprost would improve RV function via induction of VEGF-mediated angiogenesis. To test this hypothesis, RV microvessels were perfused with Texas Red-conjugated tomato (Lycopersicon esculentum) lectin, which binds and marks endothelial cells [16], and capillary density was assessed by confocal microscopy, as previously reported [16]. Iloprost treatment did not increase the percentage of perfused microvessels between the iloprost- and vehicle-treated groups, indicating that capillary rarefaction had not been 

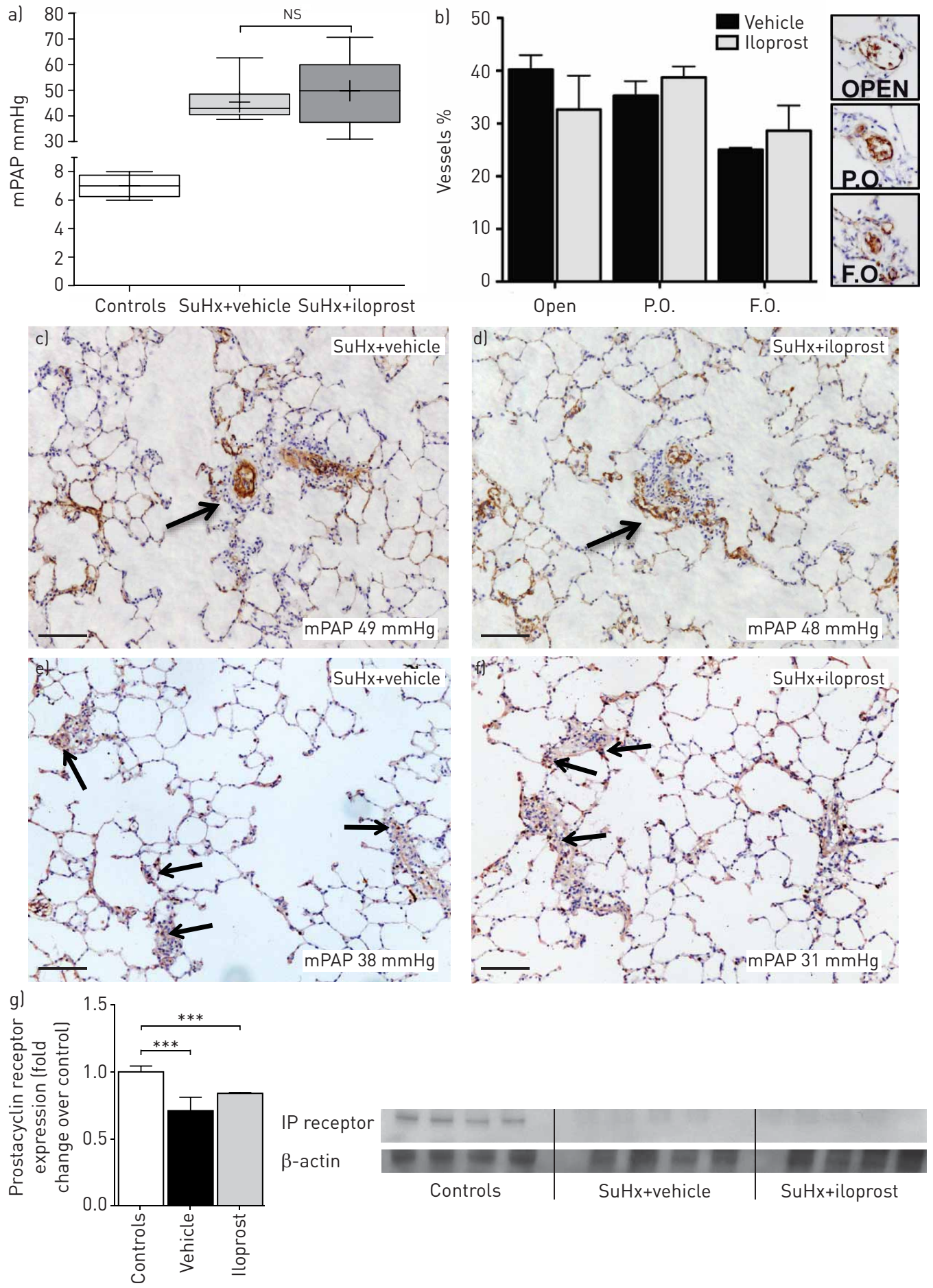

FIGURE 1 a) Mean pulmonary arterial pressure (mPAP) obtained by catheterisation was not different between iloprost and drug-free vehicle-treated groups. The boxes represent the first and third quartiles and the line across the box the median. The + symbol represents the mean and the whiskers the minimum and maximum values. b) Vascular morphometric analysis of lung tissue samples stained for von Willebrand factor (brown) showed no difference in the number of occluded or partially occluded vessels between groups. The right hand part of the panel illustrates the type of vessels that were used as references to calculate the number of open, partially obliterated (P.O.) and fully obliterated (F. O.) vessels, as previously published by Ока et al. [24]. c-d) Plexiform-like lesions were consistently present in the lungs of both iloprost and drug-free vehicle-treated rats. e-f) Lung tissue samples stained for the proliferating cell nuclear antigen (PCNA) showed a similarly increased expression of PCNA between groups. Scale bars $=100 \mu \mathrm{m} . \mathrm{g}$ ) Immunoblots from whole lung tissue protein isolates demonstrate significantly lower levels of the prostacyclin (IP) receptor in both SU5416/hypoxia $(\mathrm{SuHx})+$ vehicle and SuHx+iloprost groups compared with controls. Data are presented as mean \pm SEM. $\mathrm{n}=8-12$ rats. Ns: nonsignificant. ${ }^{* *}$ : $\mathrm{p}<0.001$. 

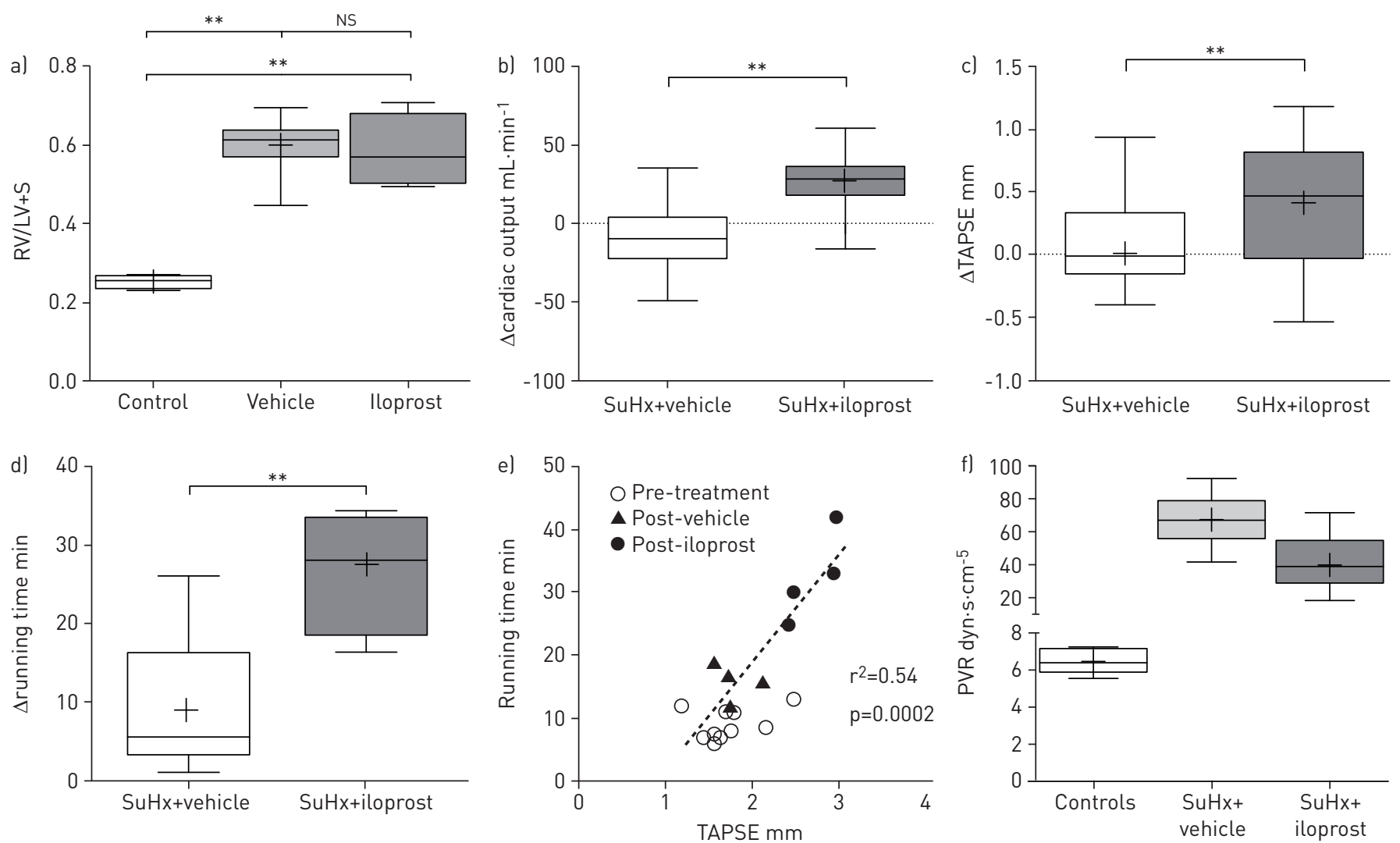

FIGURE 2 a) Right ventricle (RV) hypertrophy assessed by the Fulton index (RV/left ventricle (LV)+interventricular septum (S)) was not significantly different between groups. b) Iloprost-treated animals had a significant increase in estimated cardiac output assessed by echocardiography. c) Longitudinal contraction of the RV assessed by tricuspid annulus plane systolic excursion (TAPSE) in the echocardiogram significantly increased after iloprost treatment. d) Iloprost-treated rats exhibited significant improvement in running time during a treadmill endurance capacity test. e) Correlation of TAPSE with running time. f) Although reduced, there was no significant reduction in pulmonary vascular resistance (PVR) after iloprost treatment. Panels b-d) are presented as difference between post- and pre-treatment values per individual animal. Eight to 12 rats were used for echocardiographic studies but only four rats per group were used for treadmill running analysis. The boxes represent the first and third quartiles and the line across the box the median. The + symbol represents the mean and the whiskers the minimum and maximum values. SuHx: SU5416/hypoxia; Ns: nonsignificant. ${ }^{* *}$ : $p<0.01$.

improved (fig. 3a-d). Furthermore, we found no difference in the expression of Vegfa, Angpt1 (angiopoietin-1) or Apln (apelin), a set of pro-angiogenic factors shown to be decreased in maladaptive RV hypertrophy (fig. 3e) [28]. Because the lack of changes in gene expression and capillary density could have been explained by low (or even nonexistent) levels of iloprost in the RV, we measured the amount of the stable prostacyclin metabolite 6-keto-prostaglandin F1 $\alpha$ (6-keto-PGF1 $\alpha$ ) by chromatography electrospray ionisation tandem mass spectrometry. Figure $3 \mathrm{f}$ illustrates that the levels of 6-keto-PGF1 $\alpha$ were higher in iloprost-treated rats.

\section{Iloprost significantly reduces collagen deposition and procollagens A1A and A3 transcript levels and decreases expression of connective tissue growth factor}

Because iloprost-treated rats had a significant improvement in RV function, we postulated that mechanisms other than angiogenesis were responsible for the increase in TAPSE and treadmill exercise endurance. Indeed, histological analysis of trichromatic stained RV tissues demonstrated a striking difference in the amount of collagen deposition between iloprost- and vehicle-treated groups (fig. 4a-d). Most importantly, rats treated with iloprost had a reduced percentage of collagen deposition compared with what is normally present in SuHx RV tissues at 4 weeks (fig. 4b) [16, 21], which suggested a reversal of established RV fibrosis (fig. $4 \mathrm{a}-\mathrm{d}$ ). The quantification of the total fibrosis area over the total tissue area demonstrated a significant difference between the two groups (fig. 4e). Online supplementary figure S3 illustrates that the reduction in collagen deposition was homogenous in multiple sections of the RV. In a similar way, RV tissue from iloprost-treated rats exhibited decreased mRNA levels of the most abundant collagen forms in the cardiac extracellular matrix: procollagens A1A and A3 (fig. 4f).

Along with TGF- $\beta$, connective tissue growth factor (CTGF) regulates extracellular matrix production [29]. CTGF can directly bind the type-1 collagen promoter and induce its expression $[29,30]$. Using microarray 

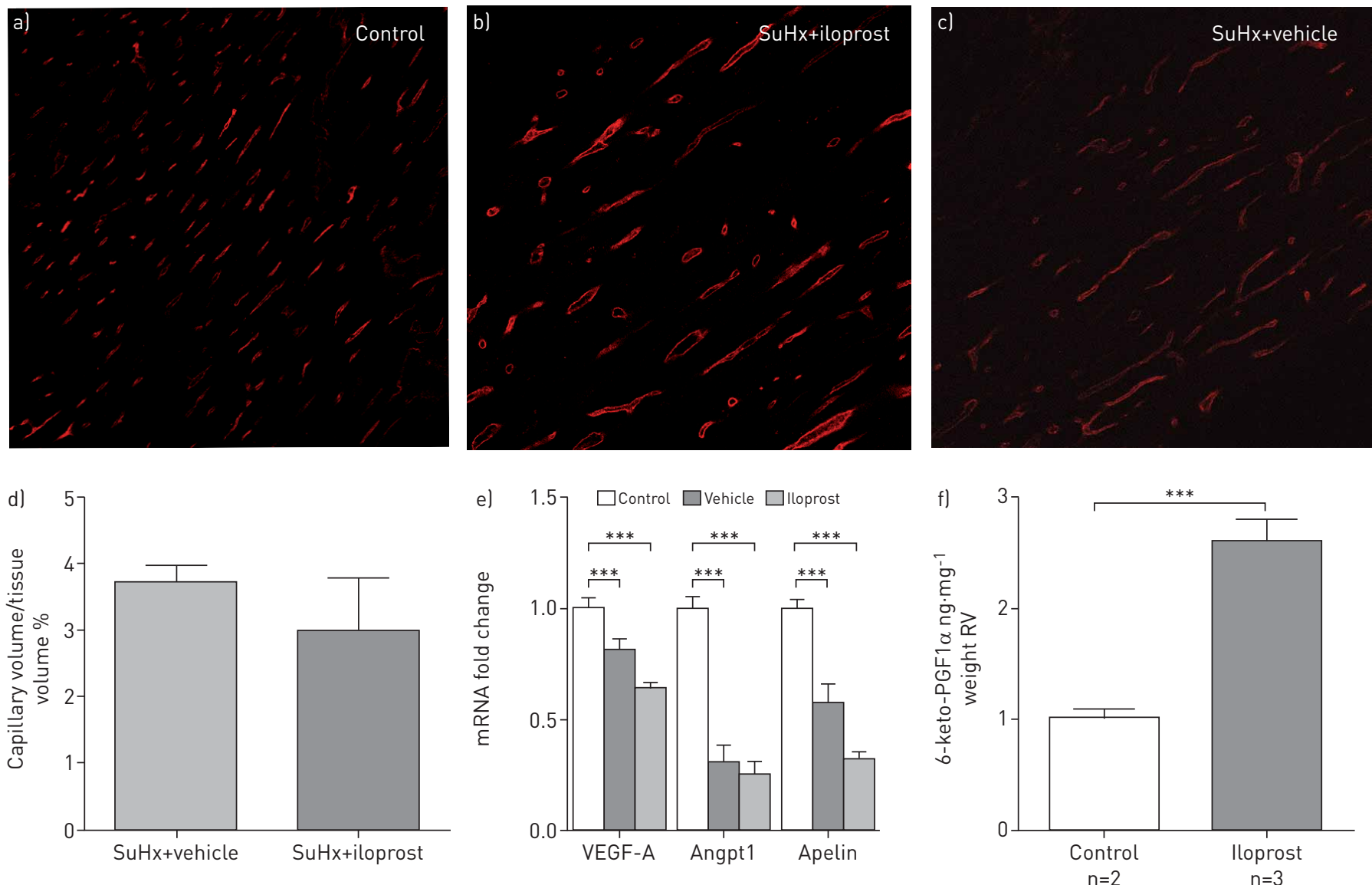

FIGURE 3 a-d) Right ventricle (RV) tissue stained with Texas Red-conjugated tomato lectin (red) demonstrated that iloprost-treated rats did not exhibit an increment in capillary density compared with vehicle-treated controls. a) Provides a reference for the capillary volume in a normal RV. e) Quantitative PCR analysis demonstrated no difference in vascular endothelial growth factor A (VEGF-A), angiopoietin-1 (Angpt1) or apelin expression after iloprost treatment. f) Chromatography electrospray ionisation tandem mass spectrometry analysis demonstrated that the stable product of prostacyclin metabolism 6-keto-prostaglandin F1 $\alpha$ (6-keto-PGF1 $\alpha$ ) was significantly increased in RV tissue obtained from iloprost-treated rats. Data are presented as mean \pm SD or mean fold change over controls \pm SEM. SuHx: SU5416/hypoxia. ${ }^{* * *}$ : $\mathrm{p}<0.001 .18$ s rRNA (Rn18s) was used as the housekeeping gene.

analysis, we have demonstrated that the expression of CTGF is markedly upregulated in maladaptive RV hypertrophy tissues compared with adaptive RV hypertrophy [28]. In addition, it has been demonstrated that iloprost can suppress the expression of CTGF in skin fibroblasts and decrease pathological fibrosis [31]. Therefore, we postulated that the reversal of RV fibrosis was partially mediated by a reduction in CTGF expression. As anticipated, CTGF gene expression was dramatically increased in maladaptive RV hypertrophy tissue and, although not completely normalised, RV tissue from iloprost-treated rats demonstrated a significant reduction in CTGF transcript and protein levels (fig. $4 \mathrm{f}-\mathrm{g}$ ). The reduction in CTGF mRNA levels correlated with TAPSE and collagen levels $\left(r^{2}=0.78, p=0.0001\right)$ (fig. S4a).

Because iloprost decreased the pulmonary vascular resistance, it is possible that transient unloading of the RV by pulmonary vasodilation reduced cardiac fibroblast mechanical stress and CTGF expression. To evaluate to what extent the effects of iloprost were explained by pulmonary vasodilation, we studied rats with increased RV afterload and a fixed pulmonary resistance. Rats were subjected to PAB surgery and were treated with iloprost or drug-free vehicle for 2 weeks, 8 weeks after surgery to allow for significant hypertrophy to develop. As previously reported [16], PAB rats did not develop signs of RV failure even after 8 weeks of pressure overload. TAPSE remained unchanged in both iloprost- and vehicle-treated groups (fig. 4h). Most importantly, RV tissues from PAB rats treated with iloprost exhibited a reduction in CTGF and procollagens A1A and A3 (fig. 4i), supporting the interpretation that the effects of iloprost in reducing CTGF and procollagen expression in the stressed RV are largely independent of pulmonary vasodilation.

\section{Iloprost reduces CTGF expression in human cardiac fibroblasts in a protein kinase A-dependent} manner

Cardiac fibroblasts are the most abundant cell type in the heart and are responsible for extracellular matrix deposition [32]. CTGF is predominantly expressed by fibroblasts (in particular myofibroblasts) [33] and 

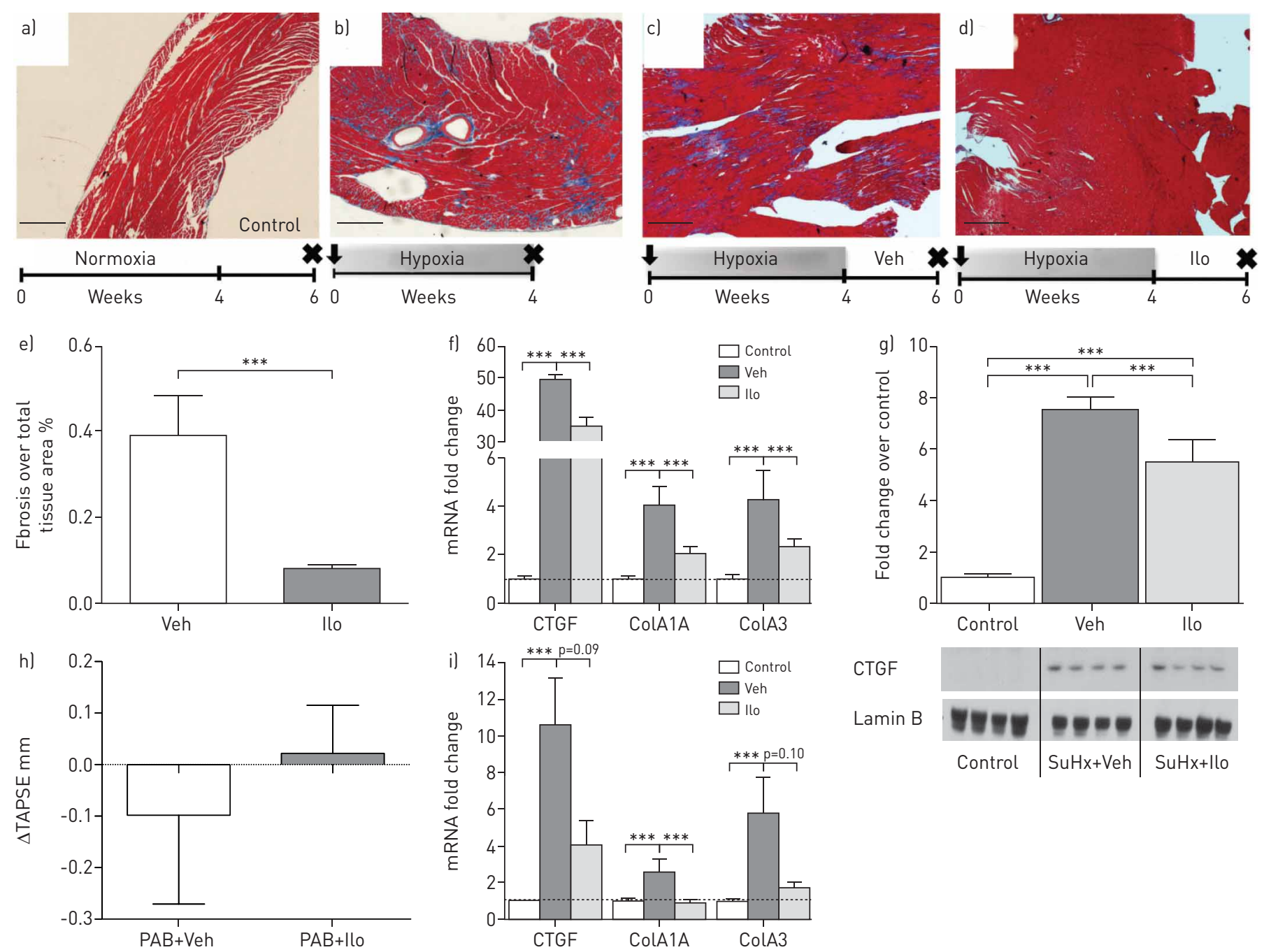

CTGF

Lamin B

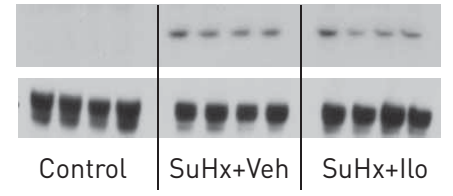

FIGURE $4 \mathrm{a}$ and b) Histological analysis of trichromatic stained slides of right ventricle (RV) tissue demonstrates that SU5416/hypoxia (SuHx) RV tissue at week 4 (b) has significantly higher collagen (blue) deposition in comparison with control RV tissue (a). The degree of collagen deposition between SuHx RV tissue at week 4 (b) was not different from SuHx RV tissue after 2 weeks of vehicle treatment (c). However, 2 weeks of iloprost treatment significantly reduced collagen deposition (d). In a-d), the arrow indicates injection of SU5416 and initiation of the protocol (see methods) and the x marks the time of sacrifice. Scale bars $=500 \mu \mathrm{m}$. e) Quantitative analysis of collagen deposition by colour deconvolution demonstrated a significant reduction in the percentage of fibrosis over the total tissue area. f) Quantitative PCR analysis demonstrated a significant reduction in connective tissue growth factor (CTGF) and the procollagen isoforms A1A (ColA1A) and A3 (ColA3) transcript levels, after iloprost (Ilo) treatment in SuHx RV tissue. g) The reduction in CTGF was also evident by Western blotting. h) There was not a significant change in tricuspid annulus plane systolic excursion (TAPSE) before and after Ilo or vehicle (Veh) control treatment in pulmonary artery banded (PAB) rats. However, similar to SuHx rats, PAB rats treated with iloprost showed a similar reduction of procollagen AlA and an important reduction in CTGF and procollagen A3 (i). Data are presented as mean fold changes over controls \pm SEM. $n=4$ rats per group for histological analysis; $\mathrm{n}=6-8$ rats for gene expression analysis, $\mathrm{n}=3$ rats per group for PAB experiments. ${ }^{* * *}$ : $\mathrm{p}<0.001$. 18s rRNA (Rn18s) was used as the housekeeping gene.

because TGF- $\beta$ plays a key role in CTGF regulation, we evaluated the effect of iloprost on human cardiac fibroblasts after exposure to rhTGF- $\beta$. As shown in figure $5 \mathrm{a}, 24 \mathrm{~h}$ of incubation with iloprost prevented the increased expression of CTGF induced by rhTGF- $\beta 1$ in a concentration-dependent manner. Similar to the in vivo experiments, the reduction in CTGF expression was associated with a decrease in procollagens A1A and A3 transcript levels (fig. 5b). Iloprost binds and activates the IP receptor, a G protein-coupled receptor that stimulates the adenylyl cyclase via Gs $\alpha$ to generate cAMP and subsequently activate protein kinase A-dependent gene expression [23]. To test whether the effect of iloprost depended on the IP receptor/ protein kinase A signalling, we co-treated cardiac fibroblasts with 8-rbs-cAMPS, an isoform of cAMP that irreversibly binds to protein kinase A, preventing its activation. Figure $5 \mathrm{c}$ demonstrates that coadministration of 8-rbs-cAMPS was sufficient to block the effect of iloprost on rhTGF- $\beta 1$-induced CTGF expression.

\section{Iloprost prevents rhTGF- $\beta 1$-induced cardiac fibroblast activation and migration}

One critically important step in the development of cardiac fibrosis is the transformation of fibroblasts into myofibroblast [33]. Myofibroblasts are smooth muscle-like fibroblasts that exhibit increased migratory 


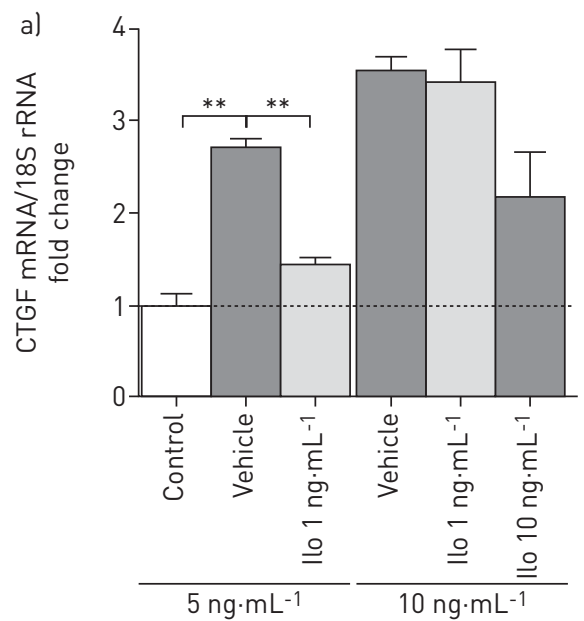

rhTGF- $\beta 1$ final concentration
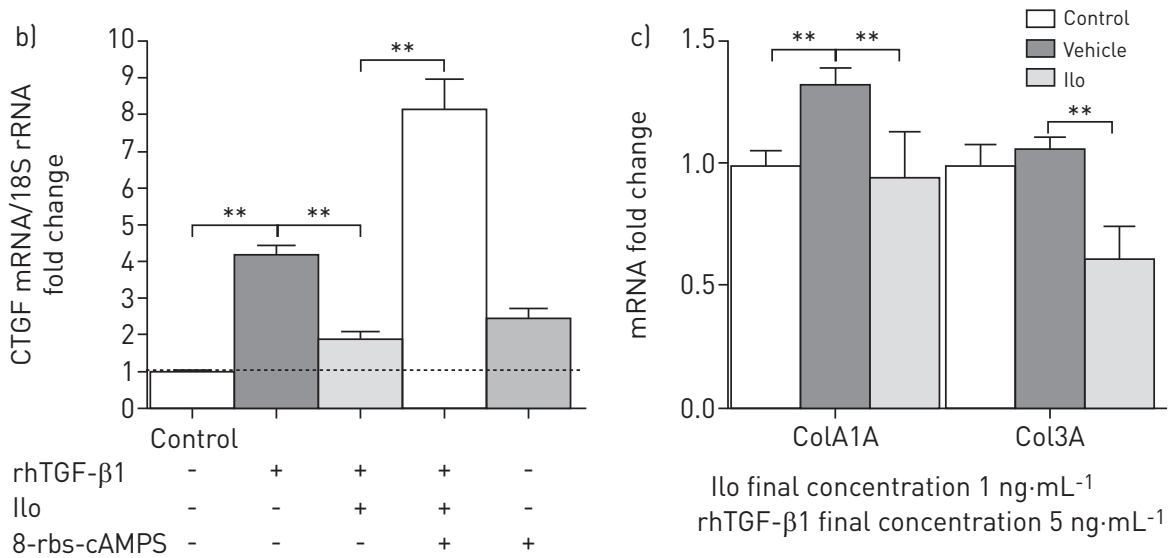

Ilo final concentration $1 \mathrm{ng} \cdot \mathrm{mL}^{-1}$ rhTGF- $\beta 1$ final concentration $5 \mathrm{ng} \cdot \mathrm{mL}^{-1}$
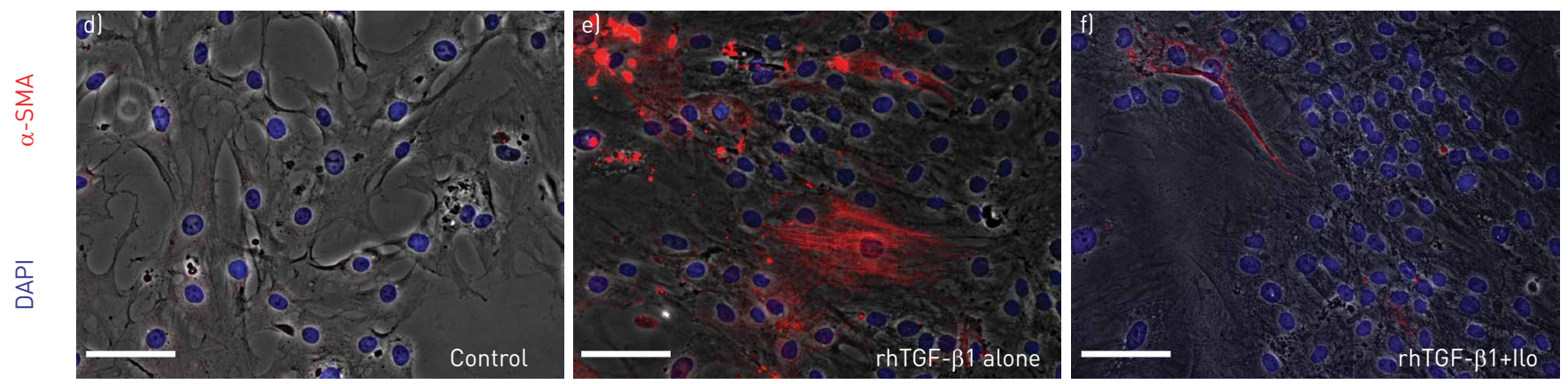

FIGURE 5 a) Effects of iloprost (Ilo; 1 or $10 \mathrm{ng} \cdot \mathrm{mL}^{-1}$ ) on connective tissue growth factor (CTGF) expression after exposure to recombinant human transforming growth factor (rhTGF)- $\beta 1$ ( 5 or $10 \mathrm{ng} \cdot \mathrm{mL}^{-1}$ ) in cultured primary human cardiac fibroblasts. b) The effect of Ilo on rhTGF- $\beta 1$-induced CTGF expression can be inhibited by co-administrating 8-bromoadenosine- $3^{\prime}, 5^{\prime}$-cyclic monophosphorothioate, Rp-isomer (8-rbs-cAMPS), a protein kinase A inhibitor. c) Similar to in vivo data, Ilo significantly reduced TGF- $\beta 1$-induced procollagens A1A and A3 transcript levels. Data are presented as mean fold changes over controls_SEM. $\mathrm{d}-\mathrm{f}$ ) Immunofluorescence micrographs demonstrate that Ilo-treated primary human cardiac fibroblasts express less $\alpha$-smooth muscle actin ( $\alpha$-SMA; red) after exposure to rhTGF- $\beta 1$ compared with vehicle controls. $4^{\prime}, 6$-diamidino-2-phenylindole (DAPI) is a fluorescent stain that binds strongly to adenine-thymine rich regions in DNA and is used to stain the cell nucleus in fluorescent microscopy studies. ColA1A: collagen A1A; Col3A: collagen $3 \mathrm{~A}$. Scale bars $=25 \mu \mathrm{m}$. ${ }^{*}: \mathrm{p}<0.01, \mathrm{n}=3$ dishes per condition.

activity, synthesise collagen and express the contractile protein $\alpha$-smooth muscle actin ( $\alpha$-SMA) [34]. Along with the reduction in expression of procollagens, iloprost-treated cardiac fibroblasts also exhibited significantly less expression of $\alpha$-SMA during co-incubation with rhTGF- $\beta 1$ (fig. $5 \mathrm{~d}-\mathrm{f}$ ). To evaluate the effects of iloprost on fibroblast migration, we used an in vitro wound closure assay as previously reported [35]. Briefly, each culture dish was scraped with a plastic pipette tip and then treated with iloprost alone at a concentration of $1 \mathrm{ng} \cdot \mathrm{mL}^{-1}$, rhTGF- $\beta 1$ at a concentration of $5 \mathrm{ng} \cdot \mathrm{mL}^{-1}$ plus vehicle (fig. $6 \mathrm{~b}$ ) or with both iloprost and rhTGF- $\beta 1$ (fig. 6c). Phase-contrast images of the identical location in each culture dish demonstrated that iloprost treatment was sufficient to reduce fibroblast migration after 12 and $24 \mathrm{~h}$ of rhTGF- $\beta 1$ exposure.

\section{Iloprost modulates matrix metalloproteinase-9 transcript levels and activity, and induces autophagy markers in the RV}

We postulated that iloprost reverses established fibrosis; therefore, we decided to evaluate whether iloprost could modulate collagen degradation. Matrix metalloproteinases (MMPs) are a family of enzymes required for normal tissue remodelling and several MMPs are expressed in the myocardium, including MMP-2 and MMP-9 [36]. MMP-2 and MMP-9 demonstrate substrate affinity for collagen and exhibit proteolytic activity against elastin and proteoglycans [36]. Iloprost significantly upregulated MMP-9 gene expression, but did not affect MMP-2 or tissue inhibitor of metalloproteinase (TIMP)-2 expression, compared with vehicle-treated controls (fig. 7a). Zymography demonstrated that protein extracts derived from the RV tissue of iloprost-treated rats exhibited markedly increased MMP-9 activity (fig. 7b). Western blotting demonstrated that TIMP-1, the main inhibitor of MMP-9 did not change significantly between treatment groups (fig. 7c). Collagen degradation is tightly regulated and multiple mechanisms for collagen 

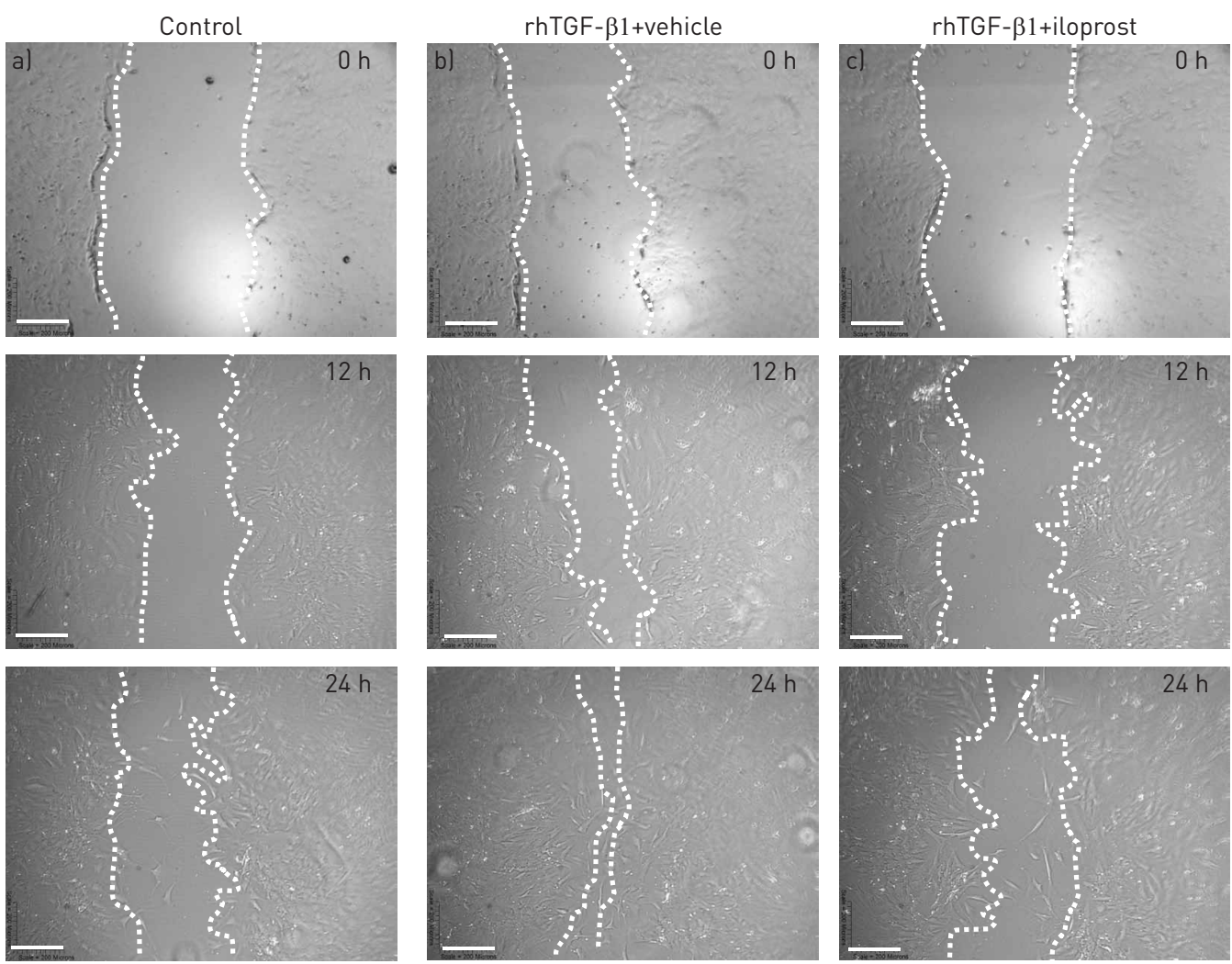

FIGURE 6 Phase contrasts images from the migration/in vitro wound closure assay demonstrated that iloprost treatment reduced recombinant human transforming growth factor (rhTGF)- $\beta 1$-induced fibroblast migration of human cardiac fibroblasts at 12 and $24 \mathrm{~h}$ after rhTGF- $\beta 1$ exposure. a) Control; b) rhTGF- $\beta 1+$ vehicle; $c$ ) rhTGF- $\beta 1+$ iloprost. $\mathrm{n}=3$ dishes per condition. Scale bars $=200 \mu \mathrm{m}$.

degradation have been described [36]. Recently, it has been reported that enhanced degradation of collagen 1 is associated with increased autophagy when the $\beta_{2}$-adrenergic receptor is activated in cardiac fibroblasts [37] and it has been demonstrated that autophagy promotes degradation of collagen 1 [38]. Thus, we hypothesised that iloprost could also contribute to collagen degradation by stimulating autophagy. RV tissues from iloprost-treated rats exhibited significantly increased gene expression of the autophagy markers p62 and LC3B (fig. 8a), increased protein levels of p62 and increased conversion of LC3B-I to LC3B-II by Western blot, the latter being a critical step for autophagosome formation [39] (fig. 8b). In vitro, cardiac fibroblasts initially stimulated with rhTGF- $\beta 1$ and treated with iloprost, as an intervention strategy, demonstrated not only significantly reduced amounts of collagen 1A but also increased expression of LC3B, which co-localised with collagen 1A (fig. 8c-e).

\section{Discussion}

RV dysfunction frequently precipitates the clinical worsening of patients with PAH and RVF is the most common cause of death in this group of patients [1]. Prostacyclin was the first treatment introduced for patients with PAH and the improvement in functional class and RV function in responding patients is usually clinically apparent within days or weeks of treatment. Here we demonstrate that a synthetic analogue of prostacyclin, iloprost, significantly improves RV function and treadmill running time in the $\mathrm{SuHx}$ rat model of severe RV failure and $\mathrm{PAH}$, without impacting the lung vascular pathology. Although inhaled iloprost treatment did not modify the expression of Vegfa and did not improve capillary density in maladaptive RV hypertrophy tissue, iloprost-treated rats exhibited a striking reduction in collagen deposition and procollagen expression, which was associated with a reduction of CTGF mRNA and protein levels. The anti-fibrotic effects of iloprost were demonstrated in two different models of chronic pressure-overload with and without a fixed vascular resistance. In vitro, treatment with iloprost prevented the expression of CTGF in human cardiac fibroblasts induced by rhTGF- $\beta 1$, in a protein kinase A-dependent manner. In addition, inhaled iloprost reduced rhTGF- $\beta 1$-induced fibroblast activation and migration. Iloprost significantly induced gene expression and the activity of cardiac MMP-9. Fianlly, we 

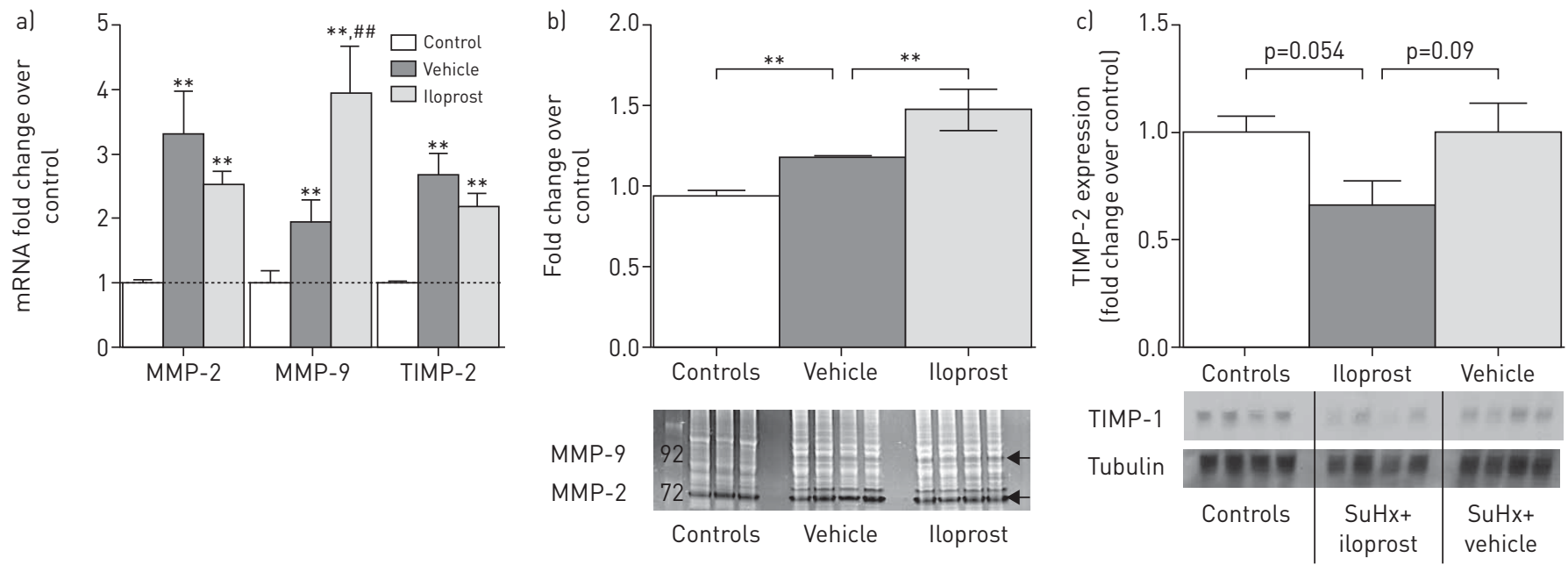

FIGURE 7 a) Quantitative PCR analysis shows a significant increase in metalloproteinase (MMP)-9 transcript levels in SU5416/hypoxia (SuHx) right ventricle (RV) tissue from iloprost-treated rats compared with drug-free vehicle controls. MMP-2 and its inhibitor (tissue inhibitor of metalloproteinase (TIMP)-2) transcript levels were significantly increased in both groups but there was no significant change after iloprost treatment. b) Zymography demonstrates increased collagenase activity for MMP-9 in RV tissue from iloprost-treated rats compared with vehicle controls. Molecular masses in kilodaltons are indicated. Arrows indicate where the respective MMPs should be located in the gel. c) Western blots from whole tissue lysate shows no significant change in TIMP-1 expression compared with drug-free vehicle-treated rats. Data are presented as mean fold changes over controls \pm SEM. ${ }^{* *}: \mathrm{p}<0.01$ versus controls; ${ }^{* \#}: \mathrm{p}<0.01$ versus drug-free vehicle-treated rats. 18s rRNA (Rn18s) was used as the housekeeping gene.
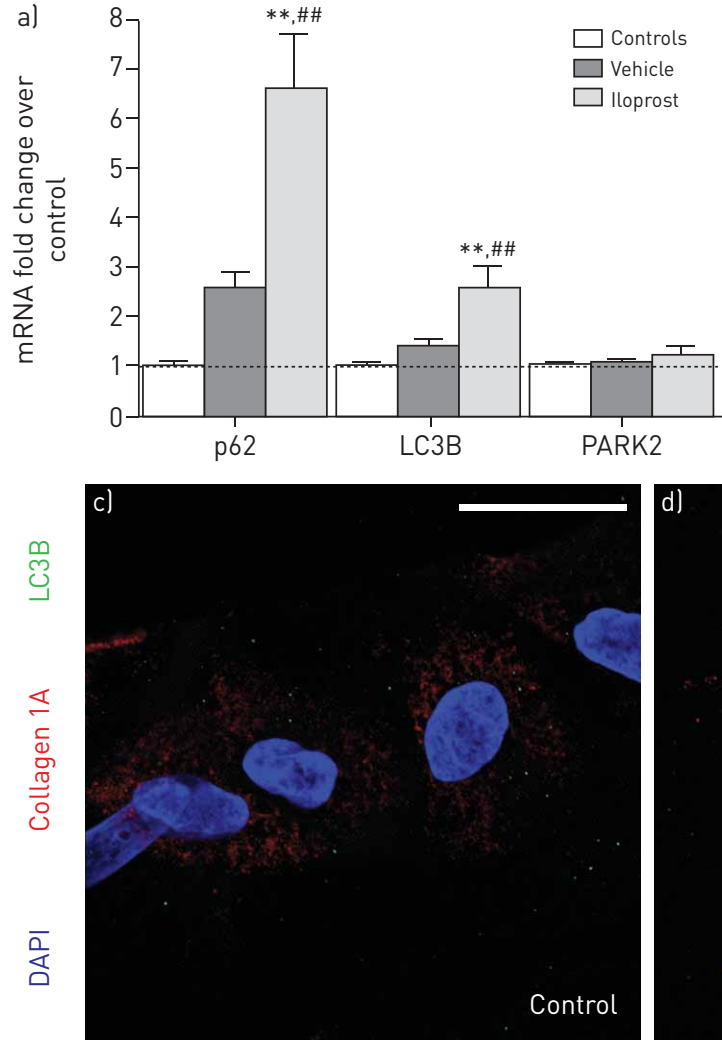

b)
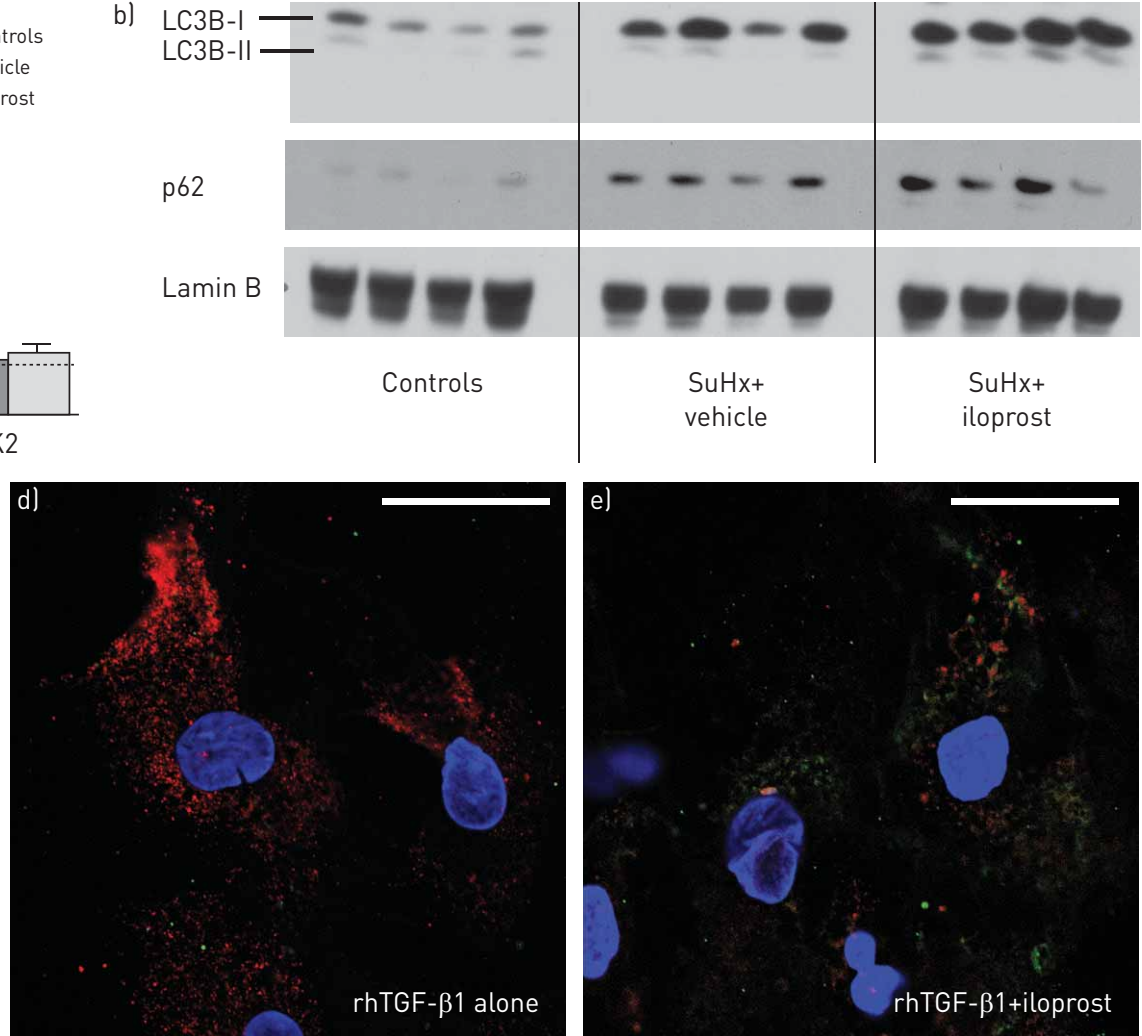

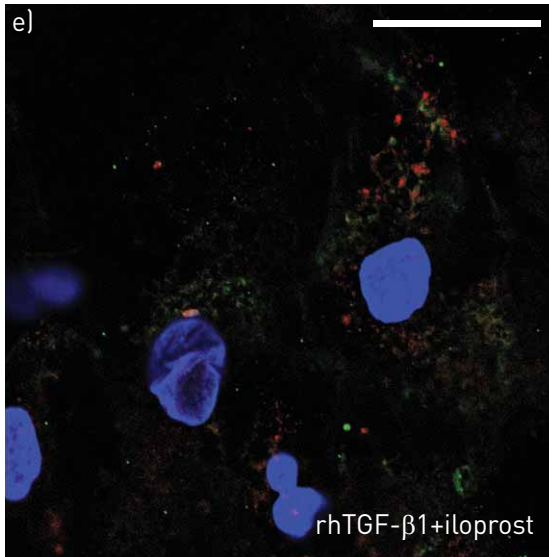

FIGURE 8 a) Quantitative PCR analysis of autophagy-related genes in SU5416/hypoxia (SuHx) right ventricle (RV) tissue shows a significant increase in p62 and LC3B, but not in PARK2 transcript levels in RV-tissues from iloprost-treated rats. b) Western blotting demonstrates increased LC3B-I conversion to LC3B-II in iloprost-treated rats and increased p62 protein level. c-e) Immunofluorescence micrographs from cardiac fibroblasts, obtained with confocal microscopy, demonstrate decreased expression of collagen Al (red) after treatment with iloprost (e). Furthermore, iloprost-treated cardiac fibroblasts demonstrated increased co-localisation of LC3B (green) and collagen A1 (red). PCR data are presented as fold changes over controls mean \pm SEM. 4',6-diamidino-2-phenylindole (DAPI) is a fluorescent stain that binds strongly to adenine-thymine rich regions in DNA and is used to stain the cell nucleus in fluorescent microscopy studies. PARK2: parkin RBR E3 ubiquitin protein ligase; rhTGF- $\beta 1$ : recombinant human transforming growth factor- $\beta 1$. Scale bars $=20 \mu \mathrm{m} .{ }^{* *}: \mathrm{p}<0.01$ versus control; ${ }^{\# \#}: \mathrm{p}<0.01$ versus vehicle. 18 s rRNA (Rn18s) was used as the housekeeping gene. 
demonstrated that iloprost induces the expression of autophagy markers, which co-localise with collagen $1 \mathrm{~A}$ in cardiac fibroblasts.

Prostacyclin, the major arachidonic acid-derived metabolite in the lung tissue [40], has been a cornerstone of PAH treatment for almost 20 years [7]. Whereas the clinical efficacy of prostacyclin treatment in patients with $\mathrm{PAH}$ has been firmly established [3], few attempts have been undertaken to elucidate the cellular and molecular mechanisms of prostacyclin action beyond its acknowledged powerful vasodilatory properties. CLAPP et al. [11] first reported the inhibitory effect of two stable prostacyclin analogues (treprostinil and iloprost) on normal lung vascular smooth muscle cell proliferation. Similar anti-proliferative properties of prostacyclin have been described when treating cells isolated from the lungs of patients with idiopathic PAH [41], even after knock-down of the IP receptor gene [42] and in mutant cells expressing a pathogenic nonsense mutation of the bone morphogenetic peptide receptor II gene [43]. However, autopsy studies have demonstrated that prostacyclin treatment does not reverse lung vascular remodelling in patients with $\mathrm{PAH}[13,14]$. Similarly, we found that inhaled iloprost treatment did not reverse lung vascular remodelling in the SuHx rat model of PAH. We propose that this discrepancy can be explained by the fact that lung vascular lesions in patients and in the SuHx rat model are composed of phenotypically altered endothelial cells, while most of the previous in vitro studies have tested the effect of prostacyclin in assays of smooth muscle cell proliferation [11, 41, 44]. Furthermore, as illustrated in figure 1 , the lungs of the SuHx rats exhibited a dramatic reduction in prostacyclin receptor levels which could explain the lack of vascular remodelling reversal.

The clinical improvement of patients with severe PAH after initiation of prostacyclin therapy is not accompanied by a significant drop in the pulmonary arterial pressure and is, therefore, difficult to explain by pulmonary vasodilation. Rather, prostacyclin treatment might induce significant RV remodelling [45]. We have previously demonstrated that maladaptive RV hypertrophy is characterised by capillary rarefaction [16] and severe RV fibrosis [21]. Because iloprost can induce the expression of VEGF in rat lungs [26], we postulated that iloprost could also induce the expression of VEGF in the RV and, thus, increase capillary density; however, to our surprise, inhaled iloprost neither increased Vegfa expression in the RV tissue of SuHx rats nor improved RV capillary rarefaction. Therefore, we turned our attention to another component believed to contribute to the pathobiology of RV failure: cardiac fibrosis.

Francois et al. [46] and HARA et al. [47] have demonstrated that transgenic mice lacking the IP receptor develop significant cardiac fibrosis, whereas mice lacking other prostaglandin receptors, such as EP [2-4], FP or TP, do not [47]. While these studies demonstrate a protective role for prostacyclins against cardiac fibrosis, it has not been investigated whether treatment with prostacyclins would be sufficient to reverse established fibrosis. Here we demonstrate that the prostacyclin analogue iloprost can reduce established cardiac fibrosis and the expression of CTGF and procollagens A1 and A3. Similar anti-fibrotic effects have been reported when treating skin fibroblasts with iloprost after exposure to TGF- $\beta$ [31] and these effects appear to be partially explained by an elevation of cAMP and a subsequent protein kinase A-dependent blockade of CTGF expression [23]. CTGF promotes fibroblast proliferation, matrix production and granulation tissue formation [48], and its role as a regulator of tissue fibrosis has been described in different organs including the heart [33]. Cardiac fibroblasts respond to mechanical stress with an upregulation of CTGF and both cardiac fibroblasts and cardiomyocytes can increase CTGF expression upon exposure to TGF- $\beta$ [49]. Similar to what has been reported for skin fibroblasts, in our studies, iloprost reduced the expression of CTGF in the $\mathrm{RV}$ of SuHx rats and in primary human cardiac fibroblasts. Although levels of CTGF were not normalised, iloprost induced a significant reduction of CTGF, which was associated with a reduction in collagen synthesis and deposition. Because of the limitations of our animal model, we cannot entirely exclude that the effects of iloprost treatment on the RV are only secondary to pulmonary vasodilation. However, the RV from PAB animals treated with iloprost exhibited a gene expression profile that resembled that of SuHx rats treated with iloprost, suggesting that the cardiac anti-fibrotic effects of iloprost can be independent of vasodilation. The fact that inhaled iloprost strikingly reduced collagen synthesis, but only partially reduced CTGF expression, suggests anti-fibrotic effects of iloprost that do not depend on CTGF. In addition to the effects seen in collagen expression, we demonstrated that iloprost induces MMP-9 gene expression and activity, which could contribute to collagen degradation. An additional anti-fibrotic component of iloprost action could be the intracellular degradation of collagen associated with the induction of autophagy. The mechanism whereby iloprost induces autophagy in the RV remains to be investigated.

\section{Study limitations}

Perhaps the most important limitation of our study is that we determined cardiac output by echocardiography. The method used to estimate cardiac output by echocardiogram relies on multiple variables including heart rate; however, we saw no significant difference in heart rate between the vehicleand iloprost-treated rats (data not shown). It also remains to be investigated whether iloprost treatment 


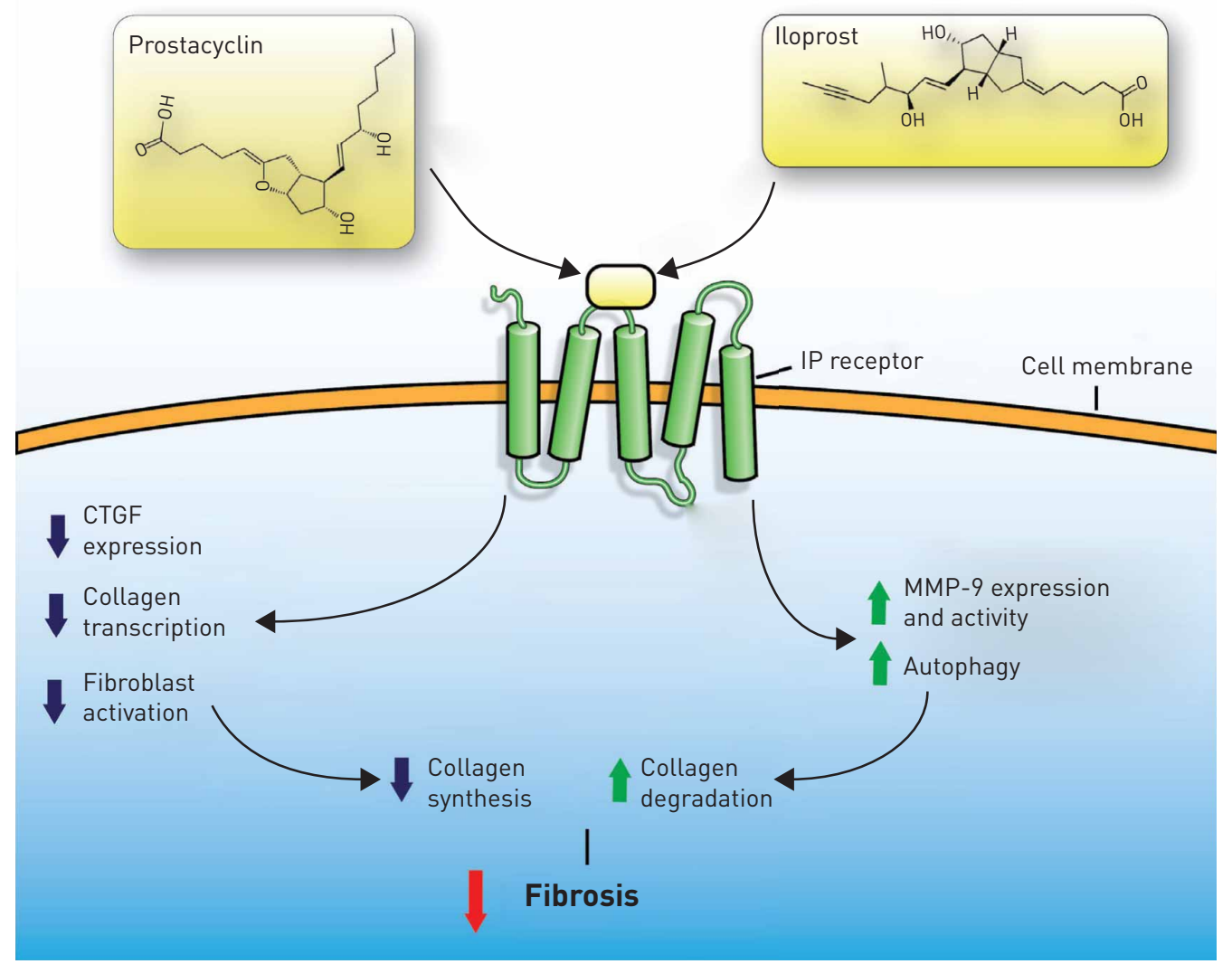

FIGURE 9 Graphical summary illustrating how prostacyclin or iloprost (yellow) bind the prostacyclin receptor (IP), a Gs protein-coupled receptor, to subsequently activate protein kinase A by increasing cAMP levels. Activation of protein kinase A prevents connective tissue growth factor (CTGF) expression, reduces the expression of procollagens and prevents fibroblast activation. Alternatively, iloprost can induce matrix metalloproteinase (MMP)-9 expression and activity, as well as autophagy-mediated collagen degradation. Taken together, in a perhaps complementary way, iloprost reverses establish fibrosis by preventing collagen synthesis and inducing collagen degradation.

improved cardiac output by improving RV compliance (i.e. improving diastolic stiffness). This could be particularly important as it has been recently demonstrated that patients with PAH-associated RV dysfunction present with significant diastolic dysfunction [50].

It remains possible that the vascular effects of iloprost might have been underestimated at the time of terminal right heart catheterisation. Indeed, although we found a nonsignificant reduction in pulmonary vascular resistance (fig. lf), the drug could have had induced a higher reduction in pulmonary vascular resistance during the course of treatment that we may have not captured. Our interpretation of the lack of change in the lectin staining of the myocardial capillaries in SuHx RV tissues after iloprost treatment could also be challenged. The diminished lectin labelling could represent a reduction in the number of functional endothelial cells available to bind lectin instead of an actual decrease in the number capillaries. Therefore, we measured the mRNA expression levels of aquaporin-1 and endothelial nitric oxide synthase, as alternative markers of functional endothelial cells, and found no difference in gene expression following iloprost treatment (data not shown), suggesting that iloprost treatment did not increase the number of lectin-stained capillaries. In addition to the anti-fibrotic effects reported here, it is also possible that iloprost affects the heart via mechanisms not investigated in our study. We interrogated our RVF transcriptional profile database $[18,28]$, but could not identify a significant expression change that could be attributable to iloprost treatment (fig. S5). However, a deeper analysis is warranted. Although we postulate that the anti-fibrotic effects of iloprost mainly affect cardiac fibroblasts, it is possible that iloprost also affects cardiomyocytes. Prostacyclins can have positive inotrope activity, as has been demonstrated experimentally in the setting of acute pulmonary hypertension [51] and in isolated cardiomyocytes [52]. Others have demonstrated a positive effect in LV contractility, but we did not find any change of the LV $\mathrm{d} P / \mathrm{d} t$ in iloprost-treated rats (fig. S2A). At the cellular level, we did not evaluate whether iloprost affected the endothelial-mesenchymal transition or reduced migration and homing of pro-fibrotic cells (i.e. fibrocytes) to the heart. Finally, whether other prostaglandin analogues possess similar anti-fibrotic 
properties or whether iloprost exerts its anti-fibrotic effects via receptors other than the IP receptor remains to be tested.

\section{Conclusions}

Our results demonstrate that inhaled iloprost improves RV function and partially reverses established RV fibrosis via two complementary mechanisms: 1) prevention of fibroblast activation and collagen synthesis; and 2) induction of collagen degradation (fig. 9). Prostacyclins (or prostacyclin analogues) may offer unique benefits for the treatment of RV dysfunction that appear to be independent of a reduction in RV pressure overload.

\section{Acknowledgements}

We would like to thank Ayser Al Hussaini, Dayanjan S. Wijesinghe and Charles E. Chalfant (Virginia Commonwealth University, Richmond, VA, USA) for the mass spectroscopy analysis of 6-keto-PGF1 $\alpha$ levels. We acknowledge Vita Kraskauskiene and Daniela Farkas (Virginia Commonwealth University, Richmond, VA, USA) for their technical support with immunohistochemistry and cell culture experiments. We would like to thank Hua Li (Virginia Commonwealth University, Richmond, VA, USA) for her help with the animal endurance tests. We acknowledge Julio Sandoval, Eleonora Mezzaroma, Stefano Toldo and Carlito Marchetti (Virginia Commonwealth University, Richmond, VA, USA) for their critical comments and technical support.

Dedicated to the memory of Robyn Barst, a pioneer of prostacyclin therapy for pulmonary arterial hypertension.

\section{References}

1 Benza RL, Miller DP, Gomberg-Maitland M, et al. Predicting survival in pulmonary arterial hypertension: insights from the Registry to Evaluate Early and Long-Term Pulmonary Arterial Hypertension Disease Management (REVEAL). Circulation 2010; 122: 164-172.

2 Voelkel NF, Gomez-Arroyo J, Abbate A, et al. Pathobiology of pulmonary arterial hypertension and right ventricular failure. Eur Respir J 2012; 40: 1555-1565.

3 Delcroix M, Spaas K, Quarck R. Long-term outcome in pulmonary arterial hypertension: a plea for earlier parenteral prostacyclin therapy. Eur Respir Rev 2009; 18: 253-259.

4 van de Veerdonk MC, Kind T, Marcus JT, et al. Progressive right ventricular dysfunction in patients with pulmonary arterial hypertension responding to therapy. J Am Coll Cardiol 2011; 58: 2511-2519.

5 Humbert M, Sitbon O, Simonneau G. Treatment of pulmonary arterial hypertension. N Engl J Med 2004; 351: $1425-1436$.

6 Hoeper MM, Schwarze M, Ehlerding S, et al. Long-term treatment of primary pulmonary hypertension with aerosolized iloprost, a prostacyclin analogue. $N$ Engl J Med 2000; 342: 1866-1870.

7 Barst RJ, Rubin LJ, Long WA, et al. A comparison of continuous intravenous epoprostenol (prostacyclin) with conventional therapy for primary pulmonary hypertension. N Engl J Med 1996; 334: 296-302.

8 Olschewski H, Simonneau G, Galiè N, et al. Inhaled iloprost for severe pulmonary hypertension. N Engl J Med 2002; 347: 322-329.

9 Olschewski H, Hoeper MM, Behr J, et al. Long-term therapy with inhaled iloprost in patients with pulmonary hypertension. Respir Med 2010; 104: 731-740.

10 McLaughlin VV, Archer SL, Badesch DB, et al. ACCF/AHA 2009 expert consensus document on pulmonary hypertension a report of the American College of Cardiology Foundation Task Force on Expert Consensus Documents and the American Heart Association developed in collaboration with the American College of Chest Physicians; American Thoracic Society, Inc.; and the Pulmonary Hypertension Association. J Am Coll Cardiol 2009; 53: 1573-1619.

11 Clapp LH, Finney P, Turcato S, et al. Differential effects of stable prostacyclin analogs on smooth muscle proliferation and cyclic AMP generation in human pulmonary artery. Am J Respir Cell Mol Biol 2002; 26: 194-201.

12 Galiè N, Manes A, Negro L, et al. A meta-analysis of randomized controlled trials in pulmonary arterial hypertension. Eur Heart J 2009; 30: 394-403.

13 Stacher E, Graham BB, Hunt JM, et al. Modern age pathology of pulmonary arterial hypertension. Am J Respir Crit Care Med 2012; 186: 261-272.

14 Pogoriler JE, Rich S, Archer SL, et al. Persistence of complex vascular lesions despite prolonged prostacyclin therapy of pulmonary arterial hypertension. Histopathology 2012; 61: 597-609.

15 Syed A, Gomez-Arroyo J, Sakagami M, et al. Inhaled iloprost improves right ventricular function in the Sugen5416/hypoxia model of severe pulmonary hypertension. Am J Respir Crit Care Med 2012; 185: A3415.

16 Bogaard HJ, Natarajan R, Henderson SC, et al. Chronic pulmonary artery pressure elevation is insufficient to explain right heart failure. Circulation 2009; 120: 1951-1960.

17 Sakao S, Taraseviciene-Stewart L, Cool CD, et al. VEGF-R blockade causes endothelial cell apoptosis, expansion of surviving $\mathrm{CD}_{3}{ }^{+}$precursor cells and transdifferentiation to smooth muscle-like and neuronal-like cells. FASEB $J$ 2007; 21: 3640-3652.

18 Gomez-Arroyo J, Mizuno S, Szczepanek K, et al. Metabolic gene remodeling and mitochondrial dysfunction in failing right ventricular hypertrophy secondary to pulmonary arterial hypertension. Circ Heart Fail 2013; 6: $136-144$.

19 Urboniene D, Haber I, Fang YH, et al. Validation of high-resolution echocardiography and magnetic resonance imaging vs. high-fidelity catheterization in experimental pulmonary hypertension. Am J Physiol Lung Cell Mol Physiol 2010; 299: L401-L412.

20 Bogaard HJ, Mizuno S, Al-Hussaini AA, et al. Suppression of histone deacetylases worsens right ventricular dysfunction after pulmonary artery banding in rats. Am J Respir Crit Care Med 2011; 183: 1402-1410.

21 Bogaard HJ, Natarajan R, Mizuno S, et al. Adrenergic receptor blockade reverses right heart remodeling and dysfunction in pulmonary hypertensive rats. Am J Respir Crit Care Med 2010; 182: 652-660. 
Gomez-Arroyo J, Saleem SJ, Mizuno S, et al. A brief overview of mouse models of pulmonary arterial hypertension: problems and prospects. Am J Physiol Lung Cell Mol Physiol 2012; 302: L977-L991.

23 inhibiting the Ras/MEK/ERK pathway. FASEB J 2002; 16: 1949-1951.

24 Oka M, Homma N, Taraseviciene-Stewart L, et al. Rho kinase-mediated vasoconstriction is important in severe occlusive pulmonary arterial hypertension in rats. Circ Res 2007; 100: 923-929.

25 Abe K, Toba M, Alzoubi A, et al. Formation of plexiform lesions in experimental severe pulmonary arterial hypertension. Circulation 2010; 121: 2747-2754.

26 Höper MM, Voelkel NF, Bates TO, et al. Prostaglandins induce vascular endothelial growth factor in a human monocytic cell line and rat lungs via cAMP. Am J Respir Cell Mol Biol 1997; 17: 748-756.

27 Voelkel NF, Hoeper M, Maloney J, et al. Vascular endothelial growth factor in pulmonary hypertension. Ann NY Acad Sci 1996; 796: 186-193.

28 Drake JI, Bogaard HJ, Mizuno S, et al. Molecular signature of a right heart failure program in chronic severe pulmonary hypertension. Am J Respir Cell Mol Biol 2011; 45: 1239-1247.

29 Leask A, Abraham DJ. The role of connective tissue growth factor, a multifunctional matricellular protein, in fibroblast biology. Biochem Cell Biol 2003; 81: 355-363.

30 Shi-Wen X, Pennington D, Holmes A, et al. Autocrine overexpression of CTGF maintains fibrosis: RDA analysis of fibrosis genes in systemic sclerosis. Exp Cell Res 2000; 259: 213-224.

31 Stratton R, Shiwen X, Martini G, et al. Iloprost suppresses connective tissue growth factor production in fibroblasts and in the skin of scleroderma patients. J Clin Invest 2001; 108: 241-250.

32 Eghbali M. Cardiac fibroblasts: function, regulation of gene expression, and phenotypic modulation. Basic Res Cardiol 1992; 87: Suppl. 2, 183-189.

33 Creemers EE, Pinto YM. Molecular mechanisms that control interstitial fibrosis in the pressure-overloaded heart. Cardiovasc Res 2011; 89: 265-272.

34 Tomasek JJ, Gabbiani G, Hinz B, et al. Myofibroblasts and mechano-regulation of connective tissue remodelling. Nat Rev Mol Cell Biol 2002; 3: 349-363.

35 Arndt S, Schmidt J, Wacker E, et al. Fussel-15, a new player in wound healing, is deregulated in keloid and localized scleroderma. Am J Pathol 2011; 178: 2622-2631.

36 Spinale FG. Myocardial matrix remodeling and the matrix metalloproteinases: influence on cardiac form and function. Physiol Rev 2007; 87: 1285-1342.

37 Aránguiz-Urroz P, Canales J, Copaja $\mathrm{M}$, et al. $\beta_{2}$-adrenergic receptor regulates cardiac fibroblast autophagy and collagen degradation. Biochim Biophys Acta 2011; 1812: 23-31.

38 Kim SI, Na HJ, Ding Y, et al. Autophagy promotes intracellular degradation of type I collagen induced by transforming growth factor (TGF)- $\beta 1$. J Biol Chem 2012; 287: 11677-11688.

39 Maiuri MC, Zalckvar E, Kimchi A, et al. Self-eating and self-killing: crosstalk between autophagy and apoptosis. Nat Rev Mol Cell Biol 2007; 8: 741-752.

40 Voelkel NF, Gerber JG, McMurtry IF, et al. Release of vasodilator prostaglandin, PGI2, from isolated rat lung during vasoconstriction. Circ Res 1981; 48: 207-213.

41 Falcetti E, Hall SM, Phillips PG, et al. Smooth muscle proliferation and role of the prostacyclin (IP) receptor in idiopathic pulmonary arterial hypertension. Am J Respir Crit Care Med 2010; 182: 1161-1170.

42 Lai YJ, Pullamsetti SS, Dony E, et al. Role of the prostanoid EP4 receptor in iloprost-mediated vasodilatation in pulmonary hypertension. Am J Respir Crit Care Med 2008; 178: 188-196.

43 Ogo T, Chowdhury HM, Yang J, et al. Inhibition of overactive transforming growth factor- $\beta$ signaling by prostacyclin analogues in pulmonary arterial hypertension. Am J Respir Cell Mol Biol 2013; 48: 733-741.

44 Pullamsetti SS, Doebele C, Fischer A, et al. Inhibition of microRNA-17 improves lung and heart function in experimental pulmonary hypertension. Am J Respir Crit Care Med 2012; 185: 409-419.

45 Rich S, Pogoriler J, Husain AN, et al. Long-term effects of epoprostenol on the pulmonary vasculature in idiopathic pulmonary arterial hypertension. Chest 2010; 138: 1234-1239.

46 Francois H, Athirakul K, Howell D, et al. Prostacyclin protects against elevated blood pressure and cardiac fibrosis. Cell Metab 2005; 2: 201-207.

47 Hara A, Yuhki KI, Fujino T, et al. Augmented cardiac hypertrophy in response to pressure overload in mice lacking the prostaglandin I2 receptor. Circulation 2005; 112: 84-92.

48 Leask A, Holmes A, Black CM, et al. Connective tissue growth factor gene regulation. Requirements for its induction by transforming growth factor-beta 2 in fibroblasts. J Biol Chem 2003; 278: 13008-13015.

49 Chen MM, Lam A, Abraham JA, et al. CTGF expression is induced by TGF-beta in cardiac fibroblasts and cardiac myocytes: a potential role in heart fibrosis. J Mol Cell Cardiol 2000; 32: 1805-1819.

50 Rain S, Handoko ML, Trip P, et al. Right ventricular diastolic impairment in patients with pulmonary arterial hypertension. Circulation 2013; 128: 2016-2025.

51 Rex S, Missant C, Claus P, et al. Effects of inhaled iloprost on right ventricular contractility, right ventriculo-vascular coupling and ventricular interdependence: a randomized placebo-controlled trial in an experimental model of acute pulmonary hypertension. Crit Care 2008; 12: R113.

52 Fontana M, Olschewski H, Olschewski A, et al. Treprostinil potentiates the positive inotropic effect of catecholamines in adult rat ventricular cardiomyocytes. Br J Pharmacol 2007; 151: 779-786. 